\title{
The Application of 5S Management in our Country Enterprise Management
}

\author{
Tian Sha \\ Economic and Management Department, Tianjin University of Science \& Technology, Tianjin \\ 300222, China \\ 315874385@qq.com
}

\begin{abstract}
Keywords: 5S management; Management system; Enterprise employees; Maximization the profit Abstract: 5S is an unique management approach of Japanese enterprises and they have made great success by using this approach. In the early 1990s, although 5S management is transferred into our country and then be promoted and popularized rapidly, it didn't reach expected effects. In order to make the 5S management come into good use, improve performance level and competitiveness enterprises of our country enterprises, the thesis expatiates on the connotation of the 5S management analyzes the present situation of using it, the existing problems and putting forward scientific and effective countermeasures of implementation of it to our country enterprises. It comes to the conclusion that in the process of implementation of $5 \mathrm{~S}$ management, a scientific and rational management system should be developed to promote the enterprises in achieve of maximum profits, combined with national conditions in our country and characteristics of the enterprises themselves.
\end{abstract}

\section{Introduction}

5S is originated in Japan, it refers to making the production factors such as site personnel, machines, materials, methods into effective management in the production and it is an unique management approach of Japanese enterprise. In 1955, the 5S slogan of Japanese is "safety starts with sorting, finally finishing consolidation". The works about 5S of Japanese come into being since in 1986, which was a shock to for the whole site management models and thus a hot wave of 5S was raised. Japanese enterprises make the 5S operation as the basis of management work and a variety of quality management methods are carried out ${ }^{[1]}$. After the Second World War, the product quality is improved quickly, which laid the economic superpower status. The 5S management gradually be recognized by the managers in our country, and is applied into our country's enterprises, though the effect is not as good as it is expected. Therefore, putting forward scientific and reasonable measures for successful implementation of 5S management to our country enterprises has become an urgent problem to solve.

\section{The Basic Connotation of 5S Management}

5S on-site management, a modern enterprise management mode, refers to SEIRI, SEITON, SEISO, SEIKETSU, SHITSUKE, also is known as "wuchang law". Because of Japanese romanization all begin with "S", English also begin with "S", so it is called $5 S^{[2]}$.

SEIRI: Starting the $5 S$ management, only to do a good job of rectification, the following several aspects of management can be continued to. Anything in the workplace is divided into necessary and unnecessary, which be made a clear and strict distinction between the two parts. The purpose of finishing is to ensure that the production materials and tools in needed are all in the scene, and that the production site is concise, materials and tools that are not necessary are being cleared.

SEITON: Things to stay being classified in good arrangement in accordance with the provisions of the location, quantity clearing, and identification effective. The key of consolidation is to live up to quantity, positioning, product as the reasonable fixation and tidiness ${ }^{[3]}$. The process of consolidation is to ensure that production tools, finished goods and raw materials and waste material is placed in the specified location when the production is completed, all required items can get in more convenient way, to keep production at the scene in a certain order. 
SEISO: Immediately following the consolidation and rectification, sweeping will need to clean the workplace thoroughly in order to keep the workplace clean and dry by remove the dirt, making product quality stable and reduce industrial injury may result in the production process. The purpose is to create a clean, relaxed working environment through cultivating the habit of personnel hygiene. One special point of cleaning process still need to strengthen is cleaning and lubrication of machine, which is the process of cleaning and also the maintenance process of machinery and equipment.

SEIKETSU: Cleaning of $5 \mathrm{~S}$ is not only the meaning of cleaning what we call, but also means maintaining and consolidating the results through the sorting, reorganization, cleaning, making the production site tidy and clean at any time ${ }^{[4]}$. Job site is clean and bright which can make the person in happy mood, which is helpful to improve the work efficiency. Not only items need to be clean, clean work are also in need to ensure that all employees in dress, the spirit of "clean" and achievement of mutual respect between colleagues.

SHITSUKE: It is the highest realm and the ultimate goal of 5S management and is also an important part of enterprise culture. Implement 5S management objective is to all staff in the production process of consciously abide by the rules and regulations of the company system, to act in accordance with the rules and regulations of the company with forming good work habits, in their daily work automatically to form a simple, security, efficient work habits.

The 5S is not independent, unrelated, they are complementary to each other, none can be dispensed. Rectification is the basis of the reorganization, reorganization is cement of rectification. Sweeping is to show the effect of rectification and consolidation, and though cleaning and accomplishment make the enterprise form a whole atmosphere of improvement, and make sure the enterprise be able to enter the benign circulation ${ }^{[5]}$.

\section{Present Situation and Existing Problems of 5S Management in Our Country Enterprise}

The Current Situation of Implementation of 5S Management in Our Country Enterprise.5S management is currently the world's relatively advanced method of management, it always ends with improving staff quality and enterprise image. The practice of 5S management can reduce the waste in the work, increase productivity and improve quality of product and human, bring the biggest profit for the enterprise. In the early 1990s, that is transferred into our country and then be promoted and popularized rapidly. The successful application of 5S management in our country is mainly the Haier group. Almost all enterprises that has slightly scale in our country has adopted the management mode, but they has largely failed to achieve the desired effect.

The Problem of Implementation of 5S Management Enterprise in Our Country. In the early 1990s, China began to promote and apply 5S management mode, but from the perspective of practical, the poor effect of application of 5S, investigating its reason mainly exist the following problems:

Certain culture formed for a long time in our country is not conducive to the development of the 5S management activities. Many people in our country enterprises including managers are only required to do the surface when they do things, ignoring the details, pursuing only for formalism. Superior leaders go to check only for the sake of inspection, skimming the surface. Subordinates do surface of the work only to cope with the check, after superior leaders leaving away, the factory will return to the original state again. But the 5S management requires paying attention to the details and doing the little things well in order that the activities can be better carried out, avoiding the kind of phenomenon that after activity being completed, things without being done in the front affects the overall. The 5S management slogan is everywhere in our country enterprises, but they aren't really adopted, only pay attention to the surface form, and therefore our country enterprises didn't not achieve the desired effect.

Recognition and understanding of 5S management is not enough. Knowing superficial, they don't have a profound understanding of the true content of the 5S management, staying in a sweeping, cleaning situation, without really understanding the ultimate purpose of $5 \mathrm{~S}$ management is to improve people's quality, improve work efficiency and bring the biggest profit. Many managers think 5S as sweeping, cleaning, not make it and production operation together. Thinking they are two different 
things, so when they are busy at work they will put it aside, without putting it on the important position and combining the two. 5S management is not only means the work environment being clean and tidy, also asking for the staff dormitory and canteen environment being clean. Only there is a clean, comfortable living environment which make employees happy, then it will arouse their interest in work, and the willing to put their energy into work to create the biggest economic profits for enterprises. It can improve the competitiveness of the enterprises.

Many enterprises doesn't form systematic engineering and written management system. Many enterprises of $5 \mathrm{~S}$ management job are mostly doing by the production management department. Production department is related to the quality of the product, so emphatically focusing on this department. Then others departments will think that this is what the production department should do, they have nothing to do with 5S, for a lack of team spirit. As we all know, 5S management not only supposed to be implemented by the production department, but all the departments of the enterprise should implement it as well. Many enterprises have no complete paperwork to make 5S management standardization. Ignoring the system construction can not truly implement 5S management. Employees don't know what to do and should not be done. Many enterprises also face serious challenges of "gap management" and "poor management". With management system backward, there is not a good implementation of $5 S$.

5S management is a gradual process, many companies go in for grandiose projects, be impatient for success, and thus lead to many problems. Only paying attention to the surface of the problem, it makes the main problem not be solved. Some enterprises, blindly use of 5S management and copy western method, not combined with their own situation, resulting in the situation" for the traditional Chinese values and aided with modern western management and technology". They didn't do well prepared for the implementation of $5 \mathrm{~S}$.

There is a lack of awareness from the leaders and ability shortage of the implementation of staff. Many managers of enterprises do not pay attention to the 5S management, it tends to be that they will put this matter on one side after the task issued to the employees, without going to manage and intervene it. Which make the employees also passivity, negative coped with, thinking this is an unimportant thing, leading to the $5 \mathrm{~S}$ management not being put into practice normally. Some enterprise managers have insufficient management ability, narrow range of knowledge, and their human quality is not high. Resulting in the case that heart spares, but capacity is insufficient. Most of the implementation of personnel is overcautious and afraid to take responsibility. They can't vigorously promote $5 \mathrm{~S}$ management. Human quality of them is mostly not high and their ability is insufficient, that seldom explore ways of solving the problem to make a successful promotion, inversely only dealing with it perfunctorily facing pressure.

\section{Countermeasures Effectively Implementation of 5S Management in Our Country Enterprise}

Combining with the present situation of $5 \mathrm{~S}$ management in our country enterprise, according to the prevalence of some problems in the implementation of 5S management, this thesis put forward the proposals to promote $5 \mathrm{~S}$ in our country from the following aspects:

Remove the Wrong Idea, Make the 5S Management Become a Corporate Culture. The final purpose of 5S management is to improve human quality, and to make enterprise managers and staff truly understand 5S management and to make it become a kind of enterprise culture. It requires business leaders or managers guide staff correctly understand of 5S management, eliminating the obstacle of the relevant personnel consciousness, improving their interest, and making them be willingness to improve. Enterprise managers should ask all employees to develop good habits and make application of this good habit to work, so it can imperceptibly apply 5S management into work, in no need of deliberately emphasizing.

Improve Staff Awareness of 5S Management With Overall Education. Vigorously promote the $5 S$ management in the enterprise so that enterprise staff can correctly understand ${ }^{[6-7]}$. Invited relevant experts in the enterprise $5 \mathrm{~S}$ to make knowledge lectures and make use of the posters, publicity column, watching videos, knowledge contests and other activities in order to develop education 
propaganda. Adopt training examination in staff to detect if they have a comprehensive understanding of 5S management. Leading the staff to visit and inspection of the companies with a successful implementation in 5S management find out the difference between them and to learn their enterprise management methods, combined with the situation of their own business, make a better management plan, effectively implementing 5S management. Improve the working environment and efficiency of workshop, making the enterprise employees work in a clean and comfortable environment, they feel more able to treat the job actively, and arouse their enthusiasm for work to create the greatest wealth for the enterprise.

Attach Great Importance to Establish Perfect Management System. Setting a clear objectives, making a perfect plan, divided clear responsibilities, division of labor in place, then, employees can understand what they should do, how can better implement management. Establishing perfect management performance evaluation system, offering a certain reward to a team and individual who perform good job, providing a certain disposition to the teams and individuals poorly implemented, that urge all employees to comply with 5S management system. To make the 5S implementation plan of the enterprise lay a deep imprint in the heart of every employee and finally it forms the habit of doing things of individual to improve the quality of employees.

5S management is a gradual process that needs perseverance, but the process also should not be too long, it will increase the enterprise personnel's lazy sex, negatively coping with, thinking it can be implemented at any time. In the process of enacted, it should be combined with the situation and characteristics of the enterprise, making a complete plan, don't blindly use of other enterprise's management style in foreign and domestic. So you can make the enterprise benefits more close to the desired effect.

Leaders Should Play a Leading Role, Select Elaborately Implementation of Personnel of Competent. Leadership should attach great importance to the 5S management, playing a leading role, so that employees will be better to do well. Knowing that $5 \mathrm{~S}$ is very important, leadership and management not only should attach great importance to the 5S management verbally, but also take action to prove it. Constantly monitored whether employees perform the management system, and adopted a policy of reward to employees who do well based on their different demand respectively, practicing a system of punishment to the employees who didn't do a good job, so that employees can understand that is a very important to management system. Leaders should also often go to the workshop and production departments to move around, which can better understand the effect of implement 5S management, actively response measures, also stimulated the staff interested in implementation of 5S management.

Implementation of personnel play a crucial role in 5S management that can make the 5S activities be better carried out. Leaders should select some personnel who positive and able to deal with problems arising from the management and going to the problem, is better able to do a good job of promoting to be implementation of personnel. Strengthen training and learning of the implementation of personnel, enriching their knowledge, they have the ability to make $5 \mathrm{~S}$ management be promoted better.

\section{The Conclusion and Prospect}

To sum up, implementation and perfection of $5 \mathrm{~S}$ management system is a long-term process, enterprises and managers must attach great importance to, and persistently push, so as to give a deep sense of improving enterprise's development. In the process of using 5S management, managers should always keep in mind that implementation of 5S management should combined with our country national condition, enterprise's own situation and the development strategy of the enterprise to form the unique enterprise culture, make the unique enterprise culture to guide every employee's behavior, in this way, the corporate can real be in good management. Therefore, the enterprise and staff should correctly understand the connotation of 5S management and the current problems existing in the management make a positive response, so that enterprises can have a better development and create greater profits. 


\section{Reference}

[1] Luis Oscar Ramos Alonso. Cultural influence in the Japanese management. An approach to human resource management. Universidad de Valladolid (Spain) (2002)

[2]Osada, T. This is Why We Start a 5S Program, in Nikkan Kogyo Shimbun(ed.), Visual Control Systems, Factory Management Series, Productivity press, Portland (1995)

[3]Ming Lei. Analyses the 5S management methods. Modern Economic Information (2009)

[4]Debashis Sarkar. 5S for service organizations and offices. ASQ Quality Pre5S (2006)

[5]Stephen J. Warwood, Graeme Knowles. An investigation into Japanese 5-S practice in UK Industry. The TQM Magazine.(2004)Oct.16, p. 17-35

[6]Shibin Wang. Talk about 5S management. The enterprise management (2002)

[7]Jim Peterson, Roland Smith. The 5S pocket guide quality resource. London: Oxford University Press,(2006)Apr.8, p. 22-44 